\title{
Efficacy and safety of testosterone replacement therapy in men with hypogonadism: A meta-analysis study of placebo-controlled trials
}

\author{
CHANGCHENG GUO*, WENYU GU*, MIN LIU, BO PENG, XUDONG YAO, BIN YANG and JUNHUAZHENG
}

Department of Urology, Shanghai Tenth People's Hospital, Tongji University School of Medicine, Shanghai 200072, P.R. China

Received April 2, 2015; Accepted November 25, 2015

DOI: $10.3892 /$ etm.2015.2957

\begin{abstract}
The purpose of the present meta-analysis was to evaluate the efficacy and safety of testosterone replacement therapy in men with hypogonadism. A search was conducted for appropriate randomized controlled trials and the data from 16 trials were pooled. The intended primary outcome of the present study was to determine the efficacy and safety of testosterone replacement therapy. The current data demonstrated that scores for Aging Male Symptoms (AMS) were significantly reduced following testosterone replacement therapy, with a mean decrease in AMS score of 1.52 [95\% confidence interval (CI), 0.72 to 2.32; $\mathrm{P}=0.0002]$. Testosterone replacement therapy increased lean body mass [mean difference (MD), 1.22; 95\% CI, 0.33 to 2.11; $\mathrm{P}=0.007]$, reduced fat mass in a non-significantly manner (MD, $-0.85 ; 95 \% \mathrm{CI},-1.74$ to $0.04 ; \mathrm{P}=0.06$ ) and significantly reduced total cholesterol $(\mathrm{MD},-0.16 ; 95 \% \mathrm{CI},-0.29$ to -0.03 ; $\mathrm{P}=0.01)$. No significant differences were identified in body weight (MD, 0.09; 95\% CI, -1.13 to $1.31 ; \mathrm{P}=0.89$ ), body mass index (MD, $0.10 ; 95 \% \mathrm{CI},-0.62$ to $0.82 ; \mathrm{P}=0.78)$ or bone mineral density (MD, $-0.01 ; 95 \% \mathrm{CI},-0.03$ to $0.02 ; \mathrm{P}=0.60$ ). Average prostate volume increased (MD, 1.58 ; $95 \% \mathrm{CI}, 0.6$ to 2.56 ; $\mathrm{P}=0.002$ ) following testosterone replacement therapy, but the levels of prostate-specific antigen (PSA) (MD, 0.10; 95\% CI, -0.03 to $0.22 ; \mathrm{P}=0.14$ ) and the International Prostate Symptom Scores (MD, 0.01; 95\% CI, -0.37 to 0.39 ; $\mathrm{P}=0.96$ ) did not change. In conclusion, testosterone replacement therapy improves quality of life, increases lean body mass, significantly decreases total cholesterol, and is well-tolerated and safe for men with hypogonadism who are exhibiting PSA levels of $<4 \mathrm{ng} / \mathrm{ml}$.
\end{abstract}

Correspondence to: Dr Bin Yang or Dr Junhua Zheng, Department of Urology, Shanghai Tenth People's Hospital, Tongji University School of Medicine, 301 Yanchang Road, Shanghai 200072, P.R. China

E-mail: yangbnju@gmail.com

E-mail: zhengjh0471@sina.com

*Contributed equally

Key words: testosterone replacement therapy, hypogonadal men, endocrinology

\section{Introduction}

Hypogonadism is a highly prevalent disease in middle-aged men and is associated with an increased risk of numerous chronic diseases, including metabolic syndrome, osteoporosis and obesity, which significantly affect quality of life (1). Male hypogonadism can chiefly be divided into two forms; these are fetal-onset male hypogonadism and late-onset hypogonadism $(\mathrm{LOH})$. Fetal-onset male hypogonadism is associated with disorders of sexual development or pubertal development (2). Associated with advanced age, $\mathrm{LOH}$ is a clinical and biochemical syndrome with characteristic low serum testosterone levels, amongst other symptoms (3). Previous studies have indicated that $\mathrm{LOH}$ has a significant effect upon quality of life, and affects the function of multiple organ systems $(4,5)$.

Testosterone replacement treatment (TRT) was first approved in 1972 by the U.S. Food and Drug Administration as a treatment for the symptoms of male hypogonadism; currently, TRT is prescribed for men diagnosed with androgen deficiency to alleviate symptoms and improve quality of life (5). Previous studies that have assessed the impact of TRT on bone mineral density, body weight, bone mass, total lean body mass, metabolic syndrome and Aging Male Symptoms (AMS) over the past decade have been highly inconsistent (6-21); thus, it remains unclear whether testosterone therapy is beneficial with regard to these features in men with hypogonadism. Furthermore, controversy remains over whether TRT is safe for long-term treatment due to the concern that higher serum testosterone presents an increased risk for prostate cancer, which has been a widely accepted hypothesis for 70 years (22). In the present study, a meta-analysis was performed to evaluate the efficacy and safety of TRT in men with hypogonadism, which may resolve a number of the current controversies in the use of this drug.

\section{Materials and methods}

Eligibility criteria. Inclusion criteria were established prior to a literature search, following the guidelines from the Quality of Reporting of Meta-Analyses conference (23). Only placebo-controlled, randomized controlled trials (RCTs) of men with testosterone deficiency that compared TRT-treated with placebo-treated patients were included. All included studies were required to provide treatment of the subjects for at least 6 months. Studies examining TRT therapy for men 
with cancer, benign prostatic hyperplasia (BPH) and diabetes were excluded, in addition to studies of men with a severe organic disease, a mental disease diagnosed by a psychiatrist (for instance, major depression currently being treated with antidepressant medication), Parkinson disease or heart failure.

Search strategy. A literature search was performed in December 2014 using the databases of Medline (www.ncbi. nlm.nih.gov/pubmed), Embase (www.elsevier.com/solutions/ embase-biomedical-research), Elsevier (www.sciencedirect. com) and the Cochrane Library (www.cochranelibrary.com). The Medline and Embase searches included only a free-text protocol using the term 'testosterone' within the 'Title' and 'Abstract' fields of the records. Furthermore, the search strategy employed the following limitations: Human subjects, English language publications, RCT publication type and publication time between January 2004 and December 2014. Searches of the Cochrane Library used the same free-text protocol using the terms 'testosterone' and 'hypogonadal' within the 'Title' and 'Abstract' fields of the records, applying no limits. All studies published between January 2004 and December 2014 were considered. A total of 1,435 records were initially collated in this study, with 272 records retrieved from the Elsevier database and 1,158 records from the Medline database and Embase. A total of 5 records were retrieved from the Cochrane Library. The records were independently reviewed by 3 authors in order to identify the studies comparing testosterone and control treatments. Furthermore, other, relevant studies cited in the reference lists of the selected studies (Fig. 1) were also evaluated.

Study selection. The quality of the randomized trials was assessed based on methods as follows: Method of randomization, method of blinding, allocation concealment, evidence of selective reporting and incomplete outcome data. Studies that were deemed of high-quality by consensus among study authors (Fig. 2) were included.

Data extraction. The first outcomes of interest were associated with the efficacy of TRT, including the AMS score, body weight (in $\mathrm{kg}$ ), body mass index (BMI), bone mineral density (in $\mathrm{g} / \mathrm{cm}^{2}$ ), total lean body mass (in $\mathrm{kg}$ ), total fat mass (in $\mathrm{kg}$ ) and total cholesterol (in $\mathrm{mg} / \mathrm{dl}$ ). AMS score was determined based on the responses to the AMS questionnaire (www.aging-males-symptoms-scale.info/documents/ question.pdf), which investigated 17 different symptoms. The second outcomes of interest were associated with the safety of TRT, including the prostate-specific antigen (PSA) level (in $\mathrm{ng} / \mathrm{ml}$ ), International Prostate Symptom Scores (IPSS), prostate volume (in $\mathrm{ml}$ ) and the nature of adverse events (mild to moderate and serious). Data extraction was independently conducted by 2 investigators, and a third reviewer would make a judgment when disagreement arose regarding eligibility, as described previously (24).

Statistical analysis. Statistical analyses were independently performed by 2 authors who were not involved in data extraction. Q-test was used to measure inter-study heterogeneity. $I^{2}$ metric was used to quantify heterogeneity, which is independent of the number of studies included in the cumulative analysis. The $\mathrm{I}^{2}$ values were $0-100 \%$, with higher values denoting a greater

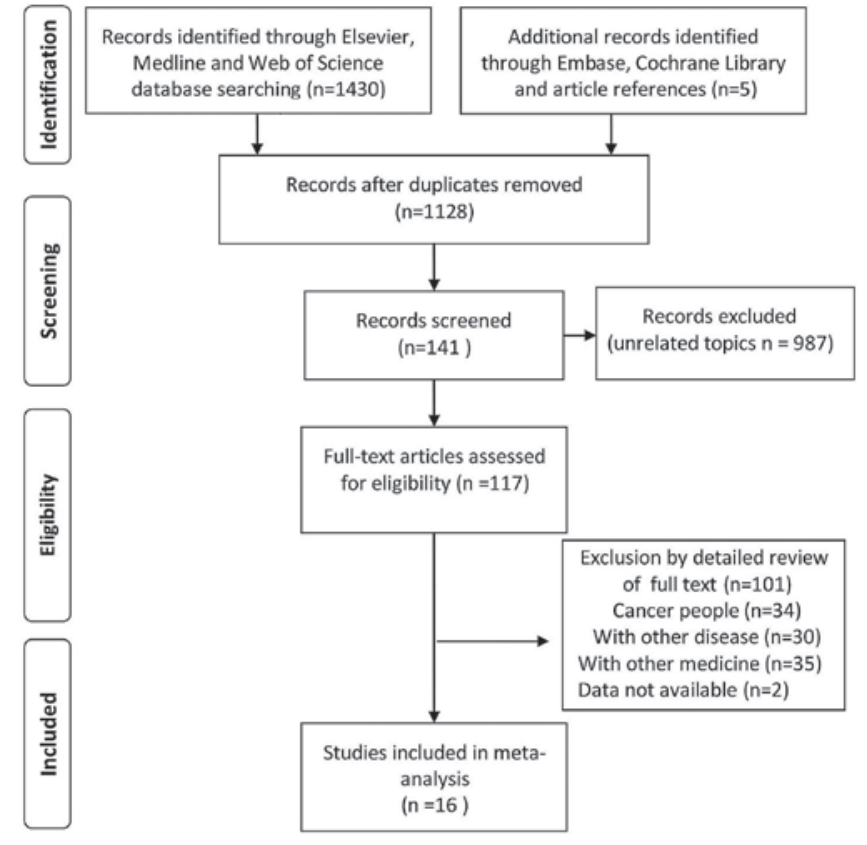

Figure 1. Flowchart of literature searches and results.

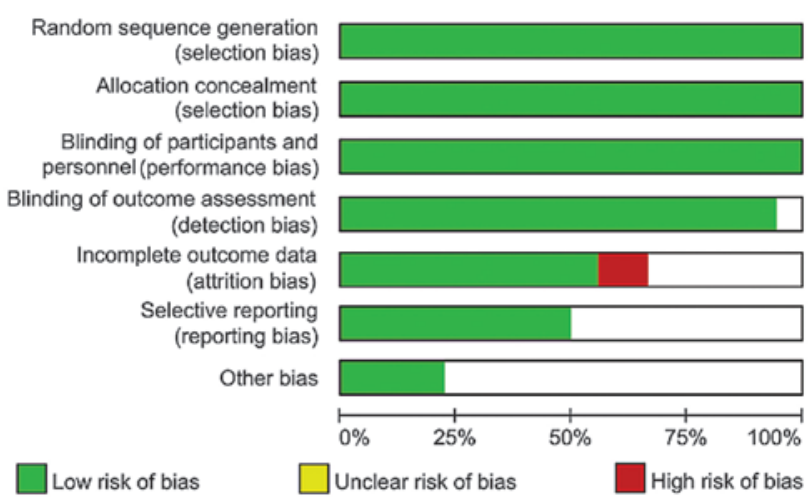

Figure 2. Risk of bias graph. Review authors' judgements regarding each risk of bias item presented as percentages across all included studies.

degree of heterogeneity. $\mathrm{I}^{2}<25 \%$ reflects a small level of inconsistency, and $\mathrm{I}^{2}>50 \%$ reflects significant inconsistency. Data were pooled using a fixed-effects model. In studies demonstrating heterogeneity, a sensitivity analysis was conducted in order to establish the cause of heterogeneity. Potential publication bias was identified using a funnel plot, which would suggest a publication bias through asymmetry of the plot. All analyses were performed using RevMan version 5.3 (Cochrane, London, UK). All P-values were calculated using Student's t-test and $\mathrm{P}<0.05$ was considered to indicate a statistically significant difference.

Subgroup and sensitivity analysis. To investigate the causes of heterogeneity, subgroup analyses were made according to the method of administration of testosterone (injection, oral, transdermal) and duration of treatment (6 months vs. $>6$ months).

\section{Results}

Identification of data. A total of 1,435 references were identified in the initial database search. As shown in Table I, 


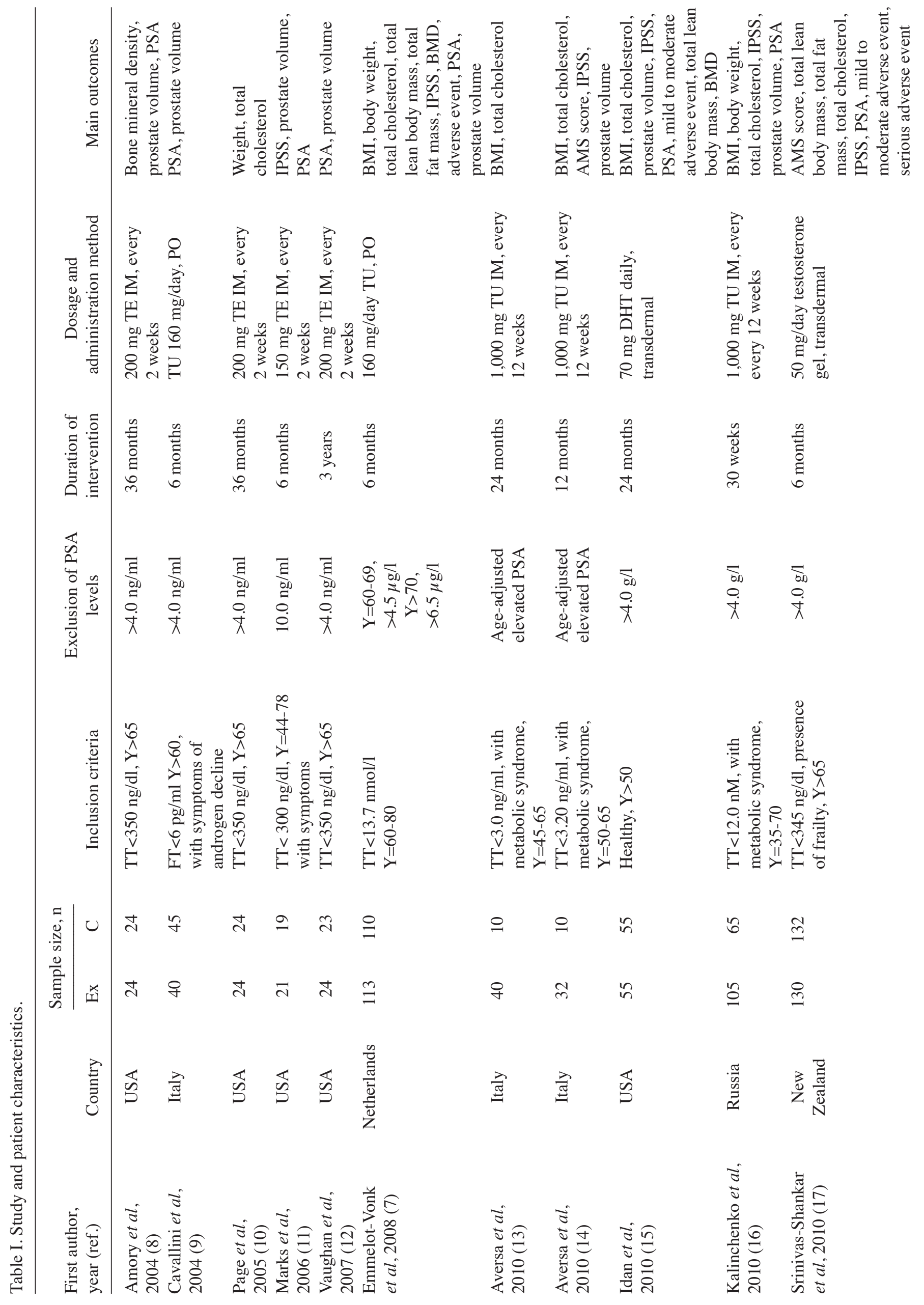




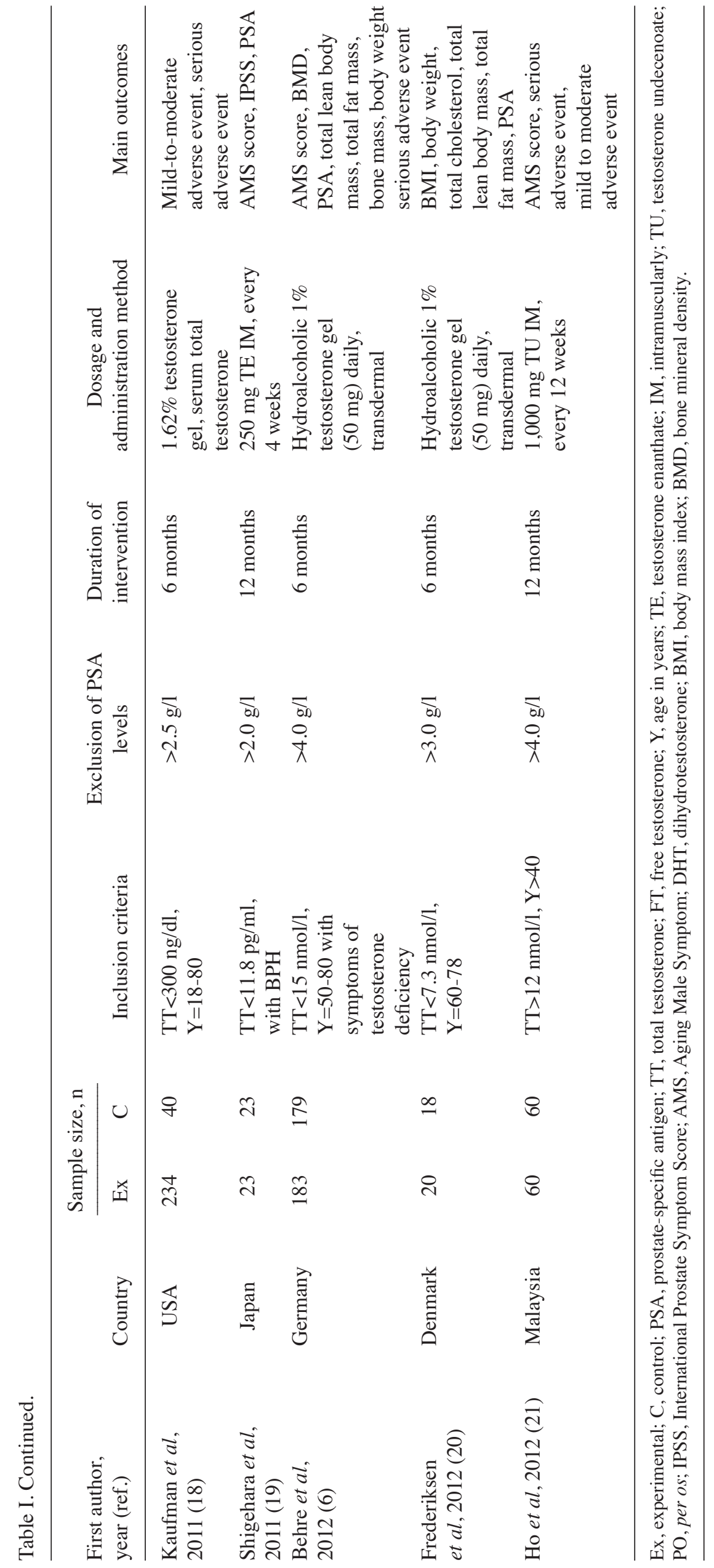




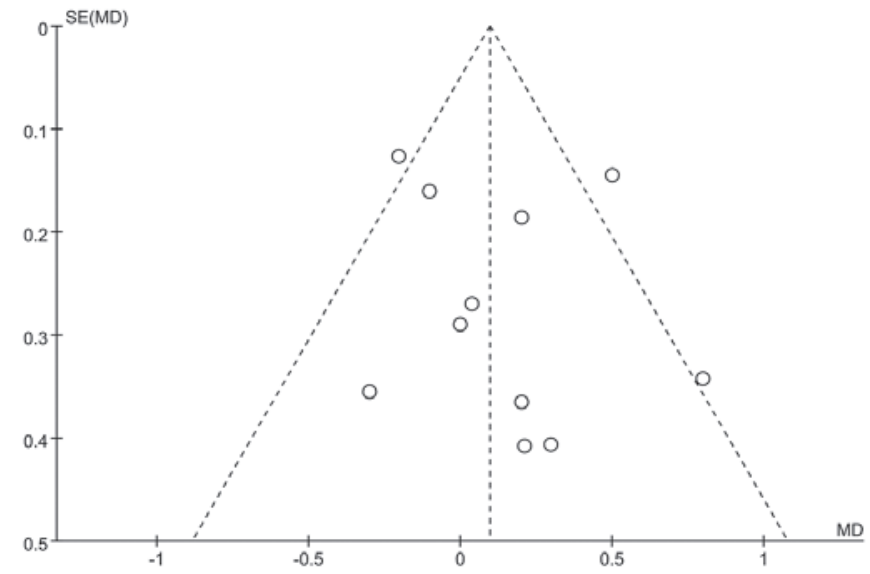

Figure 3. Funnel plot of studies, testing possible publication bias. SE, standard error; MD, mean difference.

through an abstract and full text review, 16 RCTs that met the study criteria were identified. A total of 1,921 patients were randomized across the 16 studies (Table I). All 16 RCTs were double-blinded. A total of 7 RCTs provided treatment for 6 months, with the remainder providing treatment for 1 year. A funnel plot revealed no evidence of publication bias (Fig. 3).

\section{Efficacy}

AMS score. A total of 5 RCTs, involving 826 participants (424 in the testosterone group and 402 in the control group), included AMS scores. The present data revealed that the AMS scores improved significantly following TRT. The mean decrease in AMS score was 1.52 (95\% CI, 0.72 to 2.32; $\mathrm{P}=0.0002$; Fig. 4A) following TRT. Additional analyses indicated that AMS was significantly improved in short-term studies with transdermal administration (within the same studies), but not in long-term studies with administration via injection. The average decrease in AMS score was 1.74 (95\% CI, 0.86 to 2.61; $\mathrm{P}=0.0001)$ in short-term and transdermal administration studies, and 0.40 (95\% CI, -2.37 to $1.57 ; \mathrm{P}=0.69)$ in long-term and injection studies.

Body weight. A total of 5 RCTs, involving 841 participants (445 in the testosterone group and 396 in the control group), included body weight data. No significant difference was identified in body weight between the control and the TRT group; the mean difference between these groups was 0.09 (95\% CI, -1.13 to 1.31 ; P=0.89; Fig. 4B). Subgroup analyses indicated that there was no significant change to body weight during the short-term (MD, $0 ; 95 \% \mathrm{CI},-1.25$ to 1.26 ; $\mathrm{P}=0.99)$ or the long-term (MD, $1.68 ; 95 \% \mathrm{CI},-3.86$ to 7.22 ; $\mathrm{P}=0.55)$ studies following TRT. Subgroup analyses also indicated that there were no significant changes to body weight associated with administration via injection (MD, 1.68; 95\% CI, -3.86 to $7.22 ; \mathrm{P}=0.55)$, transdermal administration (MD, $-1.01,95 \% \mathrm{CI},-2.65$ to $0.64 ; \mathrm{P}=0.23$ ) or oral administration (MD, $1.4 ; 95 \% \mathrm{CI},-0.53$ to $3.33 ; \mathrm{P}=0.38$ ).

$B M I$. BMI measurements were included in 6 RCTs, involving a total of 633 participants (365 in the testosterone group and 268 in the control group). No significant decrease was reported in BMI following TRT; the mean difference between the two groups was 0.10 (95\% CI, -0.62 to 0.82 ;
$\mathrm{P}=0.78$; Fig. 4C). The results of the subgroup analyses revealed a mean increase of 0.17 (95\% CI, -0.78 to $1.12 ; \mathrm{P}=0.73)$ during short-term studies and 0.01 (95\% CI, -1.1 to $1.12 ; \mathrm{P}=0.98)$ during long-term studies. Subgroup analyses also indicated that there were no significant differences in BMI following administration by injection (MD, 0.08 ; $95 \% \mathrm{CI},-1.32$ to 1.48 ; $\mathrm{P}=0.91)$, transdermal administration $(\mathrm{MD}, 0.14 ; 95 \% \mathrm{CI}$, -1.38 to $1.66 ; \mathrm{P}=0.86$ ) or oral administration ( $\mathrm{MD}, 0.10$; $95 \% \mathrm{CI},-0.62$ to $0.82 ; \mathrm{P}=0.85)$.

Bone mineral density. A total of $4 \mathrm{RCTs}$, involving 743 participants (375 in the testosterone group and 368 in the control group), included the bone mineral density (BMD) of patients. TRT did not increase BMD in men with hypogonadism compared with control patients. The mean difference between the two groups was -0.01 (95\% CI, -0.03 to 0.02 ; $\mathrm{P}=0.60$; Fig. 4D). Additional analysis of patients' responses to TRT administered with differing duration and administration methods revealed no statistically significant differences associated with duration of treatment (short-term: MD, -0.01; 95\% CI, -0.04 to $0.01 ; \mathrm{P}=0.31$; long-term: MD, 0.05; $95 \% \mathrm{CI},-0.02$ to $0.12 ; \mathrm{P}=0.17$ ), or with different administration methods (injection: $\mathrm{MD}, 0.05 ; 95 \% \mathrm{CI},-0.02$ to $0.12 ; \mathrm{P}=0.17$; transdermal: $\mathrm{MD},-0.02 ; 95 \% \mathrm{CI},-0.04$ to $0.01 ; \mathrm{P}=0.26$; and oral: $\mathrm{MD}, 0.0 ; 95 \% \mathrm{CI},-0.05$ to $0.05 ; \mathrm{P}=0.60)$ of TRT treatment.

Total lean body mass. A total of 5 RCTs, involving 985 participants (496 in the testosterone group and 489 in the control group), reported upon total lean body mass. Lean body mass was significantly increased following TRT; the mean difference between the two groups was 1.22 (95\% CI, 0.33 to 2.11; $\mathrm{P}=0.007$; Fig. 5A). Additional analysis of patients' response to TRT administered for different durations and via different methods indicated that TRT significantly increased lean body mass during short-term (MD, 1.04; 95\% CI, 0.11 to 1.97; $\mathrm{P}=0.03$ ) and long-term (MD, 3.13; 95\% CI, 0.07 to 6.19 ; $\mathrm{P}=0.04)$ treatment. However, no significant difference was identified in total lean body mass amongst the patients administered TRT via injection (MD, $1.7 ; 95 \% \mathrm{CI},-0.1$ to 3.5 ; $\mathrm{P}=0.06)$ and transdermally $(\mathrm{MD}, 0.65 ; 95 \% \mathrm{CI},-0.58$ to 1.88 ; $\mathrm{P}=0.30$ ). The included studies did not present any data on oral administration of TRT.

Total fat mass. A total of 5 RCTs, involving 995 participants (503 in the testosterone group and 492 in the control group), reported upon the total fat mass of patients. No statistical difference was identified between the two groups (MD, -0.85; 95\% CI, -1.74 to 0.04 ; $\mathrm{P}=0.06$; Fig. 5B). Subgroup analysis revealed no significant changes in the total fat mass between patients administered TRT transdermally (MD, $-0.91 ; 95 \% \mathrm{CI}$, -1.91 to $0.08 ; \mathrm{P}=0.07$ ) and via injection $(\mathrm{MD},-0.6 ; 95 \% \mathrm{CI}$, -2.6 to $1.4 ; \mathrm{P}=0.56)$.

Total cholesterol. A total of 8 RCTs, involving 943 participants (519 in the testosterone group and 424 in the control group), included the total cholesterol levels of patients. TRT decreased total cholesterol in the testosterone group compared with the control patients. The mean difference between the two groups was -0.16 (95\% CI, -0.29 to -0.03 ; $\mathrm{P}=0.01$; Fig. $5 \mathrm{C}$ ). Subgroup analysis revealed that total cholesterol levels significantly decreased in the long-term group (MD, -0.23; 95\% CI, -0.39 to $-0.07 ; \mathrm{P}=0.005)$. However, no significant change in total cholesterol was noted in the short-term group (MD, -0.11 ; $95 \% \mathrm{CI},-0.27$ to $0.05 ; \mathrm{P}=0.16)$. Subgroup analysis also 


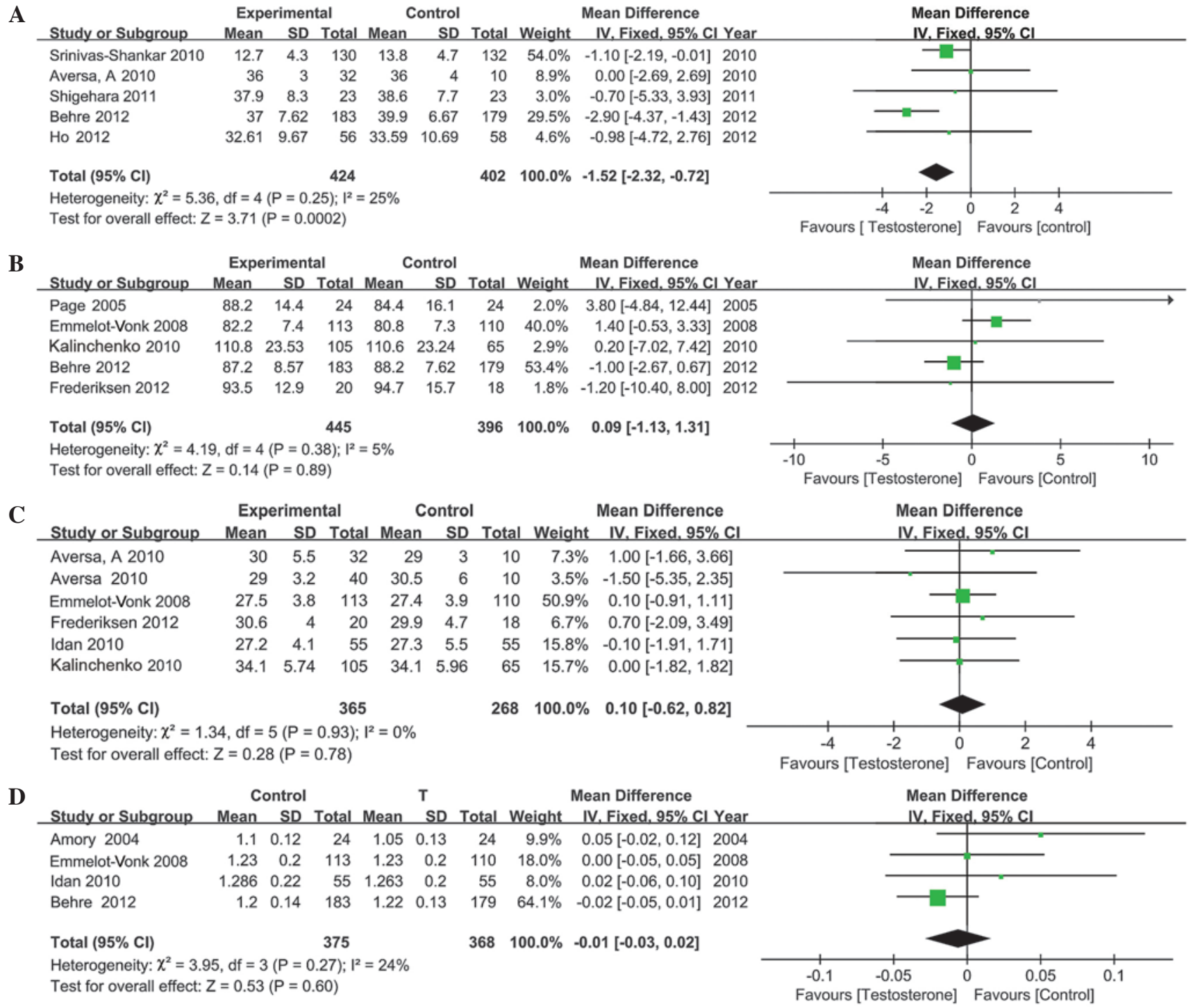

Figure 4. Forest plots revealing differences in the means of a number of variables. Differences in (A) Aging Male Symptom scores; (B) body weight; (C) body mass index; and (D) bone mineral density between experimental and control groups. SD, standard deviation; CI, confidence interval; df, degrees of freedom.

demonstrated that administration by injection $(\mathrm{MD},-0.27$; $95 \% \mathrm{CI},-0.5$ to $-0.04 ; \mathrm{P}=0.02$ ) reduced cholesterol to a greater degree than transdermally-administered (MD, $-0.18 ; 95 \% \mathrm{CI}$, -0.37 to $0.01 ; \mathrm{P}=0.07)$ and orally-administered $(\mathrm{MD}, 0$; $95 \% \mathrm{CI},-0.26$ to $0.26 ; \mathrm{P}=1.00)$ TRT.

\section{Safety}

PSA levels. A total of $11 \mathrm{RCTs}$, involving 1,392 participants (723 in the testosterone group and 669 in the control group), reported the PSA levels of patients. The present analysis revealed no significant increase in PSA levels following TRT (MD, 0.10; 95\% CI, -0.03 to 0.22; P=0.14; Fig. 5D). Subgroup analysis revealed that PSA levels did not increase following long-term TRT (MD, -0.12 ; 95\% CI, -0.32 to 0.07 ; $\mathrm{P}=0.21$ ). However, following short term TRT, the PSA levels increased significantly (MD, 0.26; 95\% CI, 0.09-0.43; P=0.002) Furthermore, transdermal administration (MD, 0.43 ; 95\% CI, 0.2 to $0.66 ; \mathrm{P}=0.0002)$ increased PSA levels more than the injection (MD, $-0.11 ; 95 \% \mathrm{CI},-0.31$ to $0.09 ; \mathrm{P}=0.27$ ) or the oral administration ( $\mathrm{MD}, 0.03 ; 95 \% \mathrm{CI},-0.21$ to $0.27 ; \mathrm{P}=0.81$ ) methods in men with hypogonadism. Following short term TRT, the prostate volume increased significantly (MD, 2.62; 95\% CI, 1.42-3.81; $\mathrm{P}=0.001)$. Furthermore, the oral administration (MD, 2.61; 95\% CI, 1.41-3.8; $\mathrm{P}=0.0001$ ) resulted in higher increase in prostate volume compared with the injection (MD, $-0.5 ; 95 \% \mathrm{CI},-2.27$ to $1.26 ; \mathrm{P}=0.58$ ) or the transdermal administration (MD, $-0.9 ; 95 \% \mathrm{CI},-8.17$ to $6.37 ; \mathrm{P}=0.81$ ) methods in men with hypogonadism.

IPSS. A total of 7 RCTs, involving 893 participants (479 in the testosterone group and 414 in the control group), provided IPSS. The present analysis indicated that, compared with the control group, TRT did not increase IPSS significantly in the experimental group (MD, $0.01 ; 95 \% \mathrm{CI},-0.37$ to 0.39 ; $\mathrm{P}=0.96$; Fig. 6A). Subgroup analysis indicated that there were no significant differences in IPSS in long-term or short-term treatment. Similarly, no significant differences in IPSS were identified within the injection (MD, $-0.01 ; 95 \% \mathrm{CI},-0.44$ to 0.42 ; $\mathrm{P}=0.95$ ), transdermal (MD, $0.35 ; 95 \% \mathrm{CI},-0.78$ to 1.47 ; $\mathrm{P}=0.55)$ or oral $(\mathrm{MD},-0.20 ; 95 \% \mathrm{CI},-1.43$ to $1.03 ; \mathrm{P}=0.96)$ administration groups. 
A

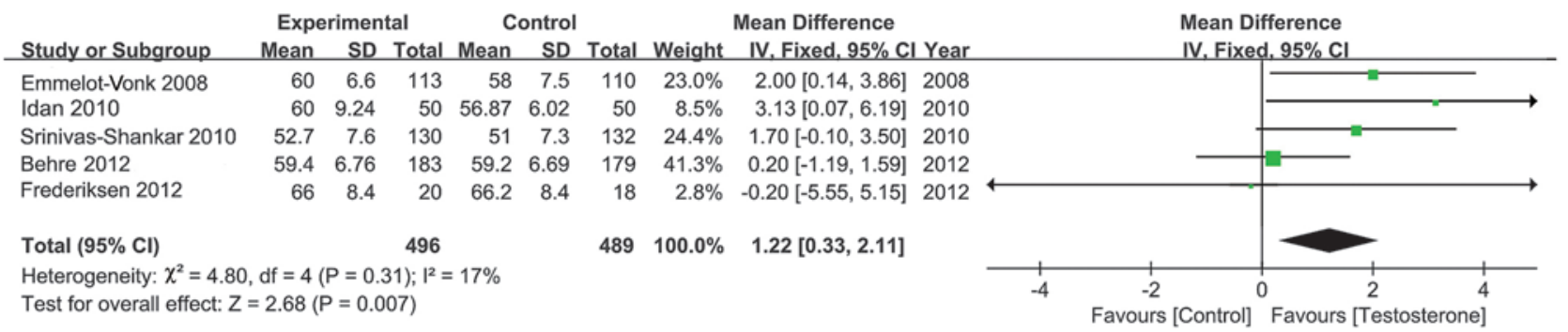

B

\begin{tabular}{|c|c|c|c|c|c|c|c|c|c|}
\hline \multirow[b]{2}{*}{ Study or Subgroup } & \multicolumn{3}{|c|}{ Experimental } & \multicolumn{2}{|c|}{ Control } & \multicolumn{4}{|c|}{ Mean Difference } \\
\hline & Mean & SD & Total & Mean & SD & Total & Weight & $95 \% \mathrm{Cl}$ & Year \\
\hline Emmelot-Vonk 2008 & 22.2 & 8.1 & 113 & 22.8 & 7.1 & 110 & $19.9 \%$ & $-0.60[-2.60,1.40]$ & 2008 \\
\hline Idan 2010 & 22.5 & 5.8 & 55 & 23 & 5.5 & 55 & $17.8 \%$ & $-0.50[-2.61,1.61]$ & 2010 \\
\hline Srinivas-Shankar 2010 & 20.6 & 7.3 & 132 & 21.5 & 7.5 & 130 & $24.7 \%$ & $-0.90[-2.69,0.89]$ & 2010 \\
\hline Frederiksen 2012 & 24.5 & 6.1 & 20 & 25.8 & 8.2 & 18 & $3.7 \%$ & $-1.30[-5.94,3.34]$ & 2012 \\
\hline Behre 2012 & 24.8 & 6.76 & 183 & 25.9 & 8.03 & 179 & $33.9 \%$ & $-1.10[-2.63,0.43]$ & 2012 \\
\hline Total $(95 \% \mathrm{Cl})$ & & & 503 & & & 492 & $100.0 \%$ & $-0.85[-1.74,0.04]$ & \\
\hline
\end{tabular}

Heterogeneity: $\chi^{2}=0.31, \mathrm{df}=4(P=0.99) ; 1^{2}=0 \%$

Test for overall effect: $Z=1.87(P=0.06)$

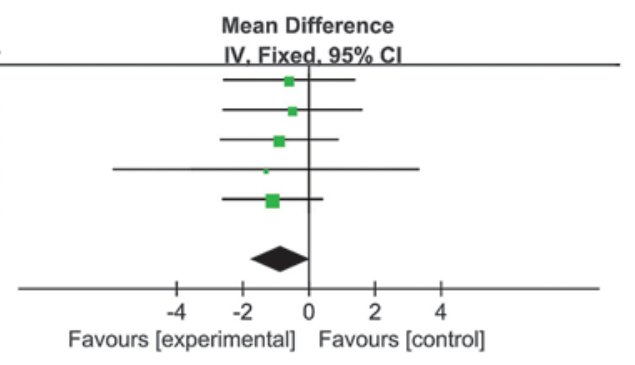

C

\begin{tabular}{|c|c|c|c|c|c|c|c|c|c|c|c|c|}
\hline \multirow[b]{2}{*}{ Study or Subgroup } & \multicolumn{3}{|c|}{ Experimental } & \multicolumn{3}{|c|}{ Control } & \multicolumn{2}{|r|}{ Mean Difference } & \multirow{2}{*}{\multicolumn{2}{|c|}{$\begin{array}{l}\text { Mean Difference } \\
\text { IV. Fixed, } 95 \% \mathrm{Cl}\end{array}$}} & & \\
\hline & Mean & SD & Total & Mean & SD & Total & Weight & IV. Fixed, $95 \%$ Cl Year & & & & \\
\hline Page 2005 & 5.21 & 1.5 & 24 & 5.63 & 1.5 & 24 & $2.3 \%$ & $-0.42[-1.27,0.43] 2005$ & & & & \\
\hline Emmelot-Vonk 2008 & 5.4 & 1 & 113 & 5.4 & 1 & 110 & $24.1 \%$ & $0.00[-0.26,0.26] 2008$ & & & & \\
\hline Kalinchenko 2010 & 5.4 & 1.3 & 105 & 5.5 & 1.23 & 65 & $11.0 \%$ & $-0.10[-0.49,0.29] 2010$ & & & & \\
\hline Aversa. 2010 & 5.17 & 0.9 & 40 & 5.29 & 1.1 & 10 & $3.1 \%$ & $-0.12[-0.86,0.62] 2010$ & & & & \\
\hline Idan 2010 & 5.1 & 1.69 & 55 & 5.25 & 1.6 & 55 & $4.4 \%$ & $-0.15[-0.77,0.47] 2010$ & & & & \\
\hline Aversa, A 2010 & 5.47 & 0.9 & 32 & 5.87 & 0.2 & 10 & $14.8 \%$ & $-0.40[-0.74,-0.06] 2010$ & & & & \\
\hline Srinivas-Shankar 2010 & 4.2 & 0.89 & 130 & 4.4 & 0.96 & 132 & $33.1 \%$ & $-0.20[-0.42,0.02] 2010$ & -1 & & & \\
\hline Frederiksen 2012 & 4.9 & 0.7 & 20 & 5 & 0.8 & 18 & $7.2 \%$ & $-0.10[-0.58,0.38] 2012$ & & & & \\
\hline Total $(95 \% \mathrm{Cl})$ & & & 519 & & & 424 & $100.0 \%$ & $-0.16[-0.29,-0.03]$ & & & & \\
\hline $\begin{array}{l}\text { Heterogeneity: } \chi^{2}=4.04 \\
\text { Test for overall effect: } Z\end{array}$ & $\begin{array}{l}\mathrm{df}=7(\mathrm{P} \\
=2.48(P\end{array}$ & $\begin{array}{l}P=0.7 \\
=0.0\end{array}$ & & & & & & & $\begin{array}{lc}-1 & -0.5 \\
\text { Favours [Testosterone] }\end{array}$ & $0^{0}$ Favours & $\begin{array}{l}0.5 \\
\text { [control] }\end{array}$ & 1 \\
\hline
\end{tabular}

D

\begin{tabular}{|c|c|c|c|c|c|c|c|c|c|}
\hline \multirow[b]{2}{*}{ Study or Subgroup } & \multicolumn{3}{|c|}{ Experimental } & \multicolumn{3}{|c|}{ Control } & \multicolumn{3}{|c|}{ Mean Difference } \\
\hline & Mean & SD & Total & Mean & SD & Total & Weight & IV. Fixed. $95 \% \mathrm{Cl}$ & $Y e$ \\
\hline Amory 2004 & 1.4 & 1.17 & 24 & 1.7 & 1.29 & 24 & $3.3 \%$ & $-0.30[-1.00,0.40]$ & \\
\hline Cavallini, G 2004 & 2 & 0.9 & 40 & 1.8 & 0.8 & 45 & $12.2 \%$ & $0.20[-0.16,0.56]$ & 2004 \\
\hline Marks 2006 & 0.9 & 0.89 & 21 & 0.6 & 1.55 & 19 & $2.6 \%$ & $0.30[-0.49,1.09]$ & 2006 \\
\hline Vaughan 2007 & 1.7 & 1.3 & 24 & 1.5 & 1.2 & 23 & $3.2 \%$ & $0.20[-0.51,0.91]$ & 2007 \\
\hline Emmelot-Vonk 2008 & 1.6 & 1.1 & 113 & 1.7 & 1.3 & 110 & $16.1 \%$ & $-0.10[-0.42,0.22]$ & 2008 \\
\hline Srinivas-Shankar 2010 & 2 & 1.4 & 130 & 1.5 & 0.9 & 132 & $19.8 \%$ & $0.50[0.21,0.79]$ & 2010 \\
\hline Kalinchenko 2010 & 0.8 & 0.78 & 104 & 1 & 0.82 & 65 & $26.0 \%$ & $-0.20[-0.45,0.05]$ & 2010 \\
\hline Idan 2010 & 1.8 & 1.54 & 55 & 1.8 & 1.5 & 55 & $5.0 \%$ & $0.57,0.57]$ & 2010 \\
\hline Shigehara 2011 & 1.38 & 0.76 & 23 & 1.34 & 1.05 & 23 & $5.8 \%$ & $0.04[-0.49,0.57]$ & 2011 \\
\hline Behre 2012 & 1.44 & 3.85 & 169 & 1.23 & 3.48 & 155 & $2.5 \%$ & $0.21[-0.59,1.01]$ & 2012 \\
\hline Frederiksen 2012 & 1.9 & 1.2 & 20 & 1.1 & 0.9 & 18 & $3.6 \%$ & $0.80[0.13,1.47]$ & 201 \\
\hline Total $(95 \% \mathrm{Cl})$ & & & 723 & & & 669 & $0.0 \%$ & $0.10[-0.03,0.22]$ & \\
\hline
\end{tabular}

Heterogeneity: $\chi^{2}=20.93, \mathrm{df}=10(P=0.02) ; 1^{2}=52 \%$

Test for overall effect: $Z=1.48(P=0.14)$

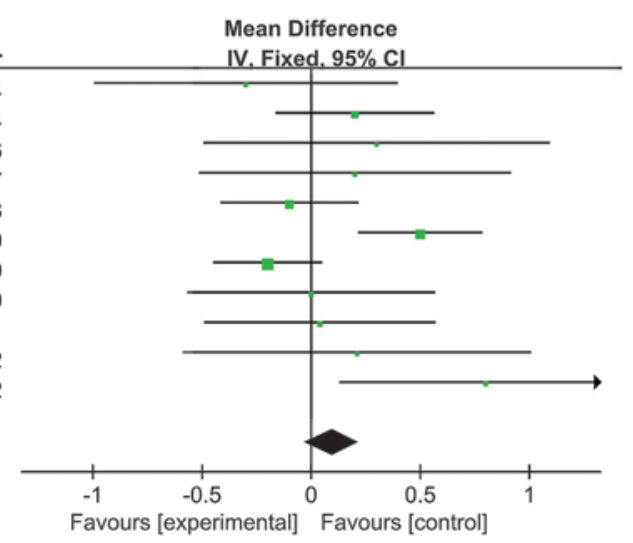

Figure 5. Forest plots revealing differences in the means of a number of variables. Differences in (A) total lean body mass; (B) fat mass; (C) total cholesterol; and (D) prostate-specific antigen levels between experimental and control groups. SD, standard deviation; CI, confidence interval; df, degrees of freedom.

Prostate volume. A total of 8 RCTs, involving 663 participants (355 in the testosterone group and 308 in the control group), included the results of prostate volume. The data revealed that the average increase in prostate volume was 1.58 (95\% CI, 0.6 to 2.56; P=0.002; Fig. 6B) following TRT. However, no significant difference in prostate volume was reported following long-term TRT (MD, $-0.55 ; 95 \% \mathrm{CI},-2.27$ to 1.17 ; $\mathrm{P}=0.96)$.

Mild to moderate adverse events. A total of 6 RCTs, involving 1,351 participants (775 in the testosterone group and 576 in the control group), included details of mild to moderate adverse events (Table II). Analysis demonstrated that the frequency of mild to moderate adverse events in the testosterone group was higher than in the control group
(MD, 1.58; 95\% CI, 1.07 to 2.33 ; $\mathrm{P}=0.02$; Fig. 6C), particularly in patients undergoing long-term treatment (MD, 3.10; 95\% CI, 1.14 to $8.41 ; \mathrm{P}=0.03$ ). However, no significant differences were reported in the number of mild to moderate adverse events in the short-term studies (MD, 1.38; 95\% CI, 0.90 to $2.11 ; \mathrm{P}=0.15)$. Subgroup analyses demonstrated that these adverse events occurred more frequently in the transdermal administration group compared with the other administration groups.

Serious adverse events. Serious adverse events reported in the included studies were: Cancer, mortality, pulmonary embolism, myocardial infarction, heart failure, constrictive pericarditis, elective surgery for intervertebral disc, inguinal hernia repair and deep vein thrombosis. 
A

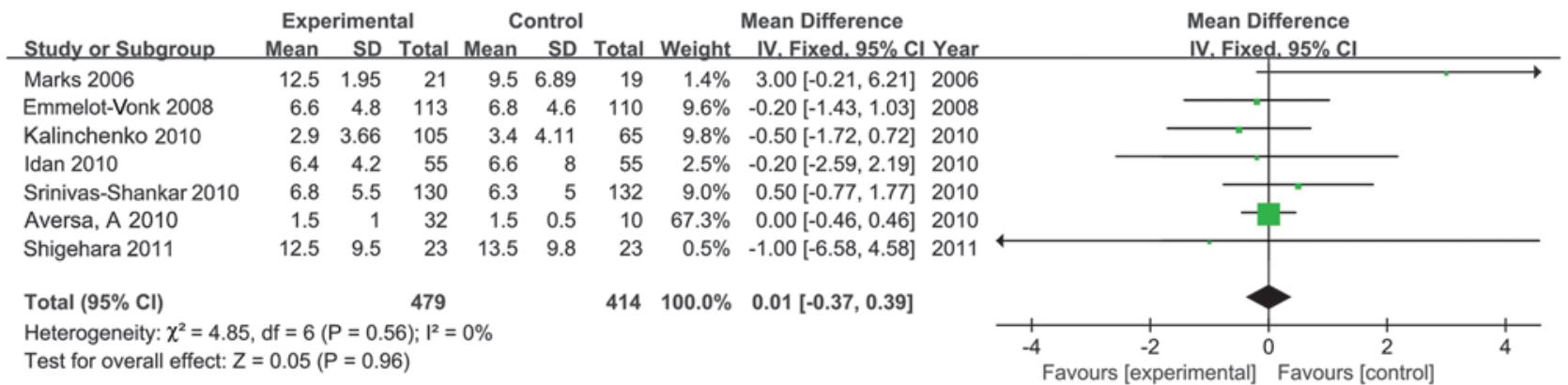

B

\begin{tabular}{lrrrrrr} 
& \multicolumn{3}{c}{ Experimental } & \multicolumn{3}{c}{ Control } \\
Study or Subgroup & Mean & SD & Total & Mean & SD & To \\
\hline Cavallini, G 2004 & 18.4 & 2.8 & 40 & 15.6 & 3.3 & \\
Amory 2004 & 43 & 14.99 & 24 & 42 & 16.25 & \\
Marks 2006 & 42 & 72.6 & 21 & 29.4 & 55.7 & \\
Vaughan 2007 & 41 & 15 & 24 & 42 & 12 & \\
Emmelot-Vonk 2008 & 30.7 & 13.1 & 113 & 29.2 & 10.4 & 1 \\
Aversa, A 2010 & 26 & 3.5 & 32 & 26 & 2.5 & \\
Kalinchenko 2010 & 28.3 & 10.2 & 46 & 33.4 & 11.24 \\
Idan 2010 & 38.1 & 16.31 & 55 & 39 & 22.14 \\
Total (95\% CI) & & & 355 & & &
\end{tabular}
Mean Difference
IV. Fixed. 95\% Cl Year

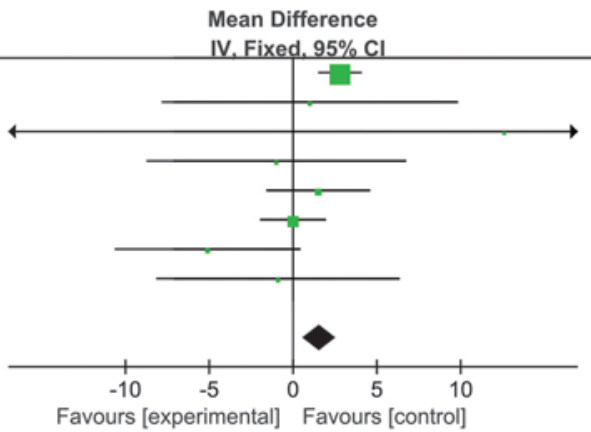

Test for overall effect: $Z=3.16(P=0.002)$

$45 \quad 57.2 \% \quad 2.80[1.50,4.10] 2004$

$24 \quad 1.2 \% \quad 1.00[-7.84,9.84] 2004$

$19 \quad 0.1 \% \quad 12.60[-27.29,52.49] 2006$

$23 \quad 1.6 \% \quad-1.00[-8.75,6.75] 2007$

$10 \quad 10.0 \% \quad 1.50[-1.60,4.60] 2008$

$10 \quad 24.9 \% \quad 0.00[-1.97,1.97] 2010$

$22 \quad 3.1 \% \quad-5.10[-10.65,0.45] 2010$

$55 \quad 1.8 \% \quad-0.90[-8.17,6.37] 2010$

$308 \quad 100.0 \%$

$1.58[0.60,2.56]$

$\begin{array}{llll}\text { C } & \text { Experimental } & \text { Control } & \text { Odds Ratio } \\ \text { Study or Subgroup } & \text { Events Total Events Total Weight M-H. Fixed. } 95 \% \mathrm{Cl} \text { Year }\end{array}$

Odds Ratio

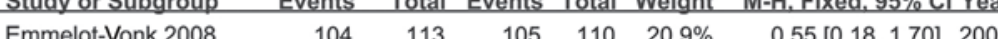

$\begin{array}{lrrrrrrr}\text { Emmelot-Vonk 2008 } & 104 & 113 & 105 & 110 & 20.9 \% & 0.55[0.18,1.70] & 2008 \\ \text { Srinivas-Shankar 2010 } & 10 & 130 & 7 & 132 & 15.8 \% & 1.49[0.55,4.04] & 2010\end{array}$

$\begin{array}{lllllll}\text { Idan } 2010 & 13 & 55 & 5 & 55 & 9.4 \% & 3.10[1.02,9.39] 2010\end{array}$

$\begin{array}{llllllll}\text { Kaufman } 2011 & 130 & 234 & 15 & 40 & 28.1 \% & 2.08[1.04,4.15] & 2011\end{array}$

$\begin{array}{lllllll}\text { Behre } 2012 & 12 & 183 & 10 & 179 & 23.3 \% & 1.19[0.50,2.82] \\ 2012\end{array}$

$\begin{array}{lllllll}\text { Ho } 2012 & 3 & 60 & 1 & 60 & 2.3 \% & 3.11[0.31,30.73]\end{array}$

$\begin{array}{lllll}\text { Total }(95 \% \mathrm{Cl}) & 775 & 576 & 100.0 \% & 1.58[1.07,2.33]\end{array}$

$\begin{array}{lr}\text { Total events } \quad 272 & 143 \\ \text { Heterogeneity: } \chi^{2}=6.16, d f=5(P=0.29) ; I^{2}=19 \%\end{array}$

Test for overall effect: $Z=2.29(P=0.02)$

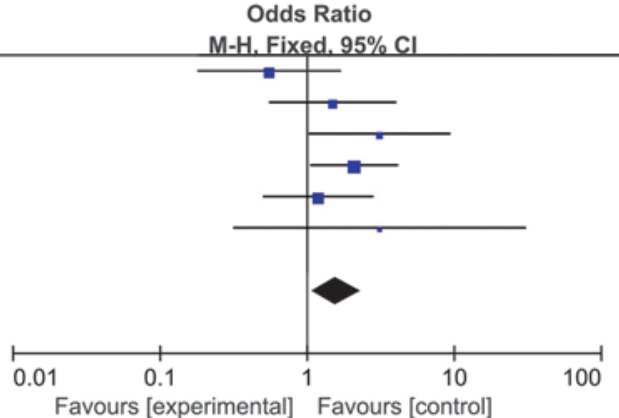

D

Experimental Control

Study or Subgroup Events Total Events Total Weight M-H. Fixed, $95 \% \mathrm{CI}$ Year

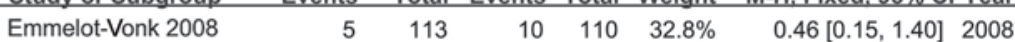

Srinivas-Shankar $2010 \quad 6 \quad \begin{array}{llllll}130 & 3 & 132 & 9.6 \% & 2.08[0.51,8.50] & 2010\end{array}$

Idan 2010

$\begin{array}{lllllll}\text { Kaufman } 2011 & 11 & 234 & 0 & 40 & 2.7 \% & 4.17[0.24,72.13] \\ 2011\end{array}$

$\begin{array}{llrrr}8 & 55 & 11 & 55 & 31.8 \%\end{array}$

$0.68[0.25,1.85] 2010$

Ho 2012

Behre 2012

$\begin{array}{rrrrr}1 & 60 & 1 & 60 & 3.3 \%\end{array}$

$4.17[0.24,72.13] 2011$

$1.00[0.06,16.37] 2012$

$1.15[0.38,3.48] 2012$

Total $(95 \% \mathrm{Cl})$

$7 \quad 183$

$6 \quad 179 \quad 19.7 \%$

$576 \quad 100.0 \% \quad 0.94[0.56,1.58]$

Total events $38 \quad 31$

Heterogeneity: $\chi^{2}=4.37, \mathrm{df}=5(P=0.50) ; 1^{2}=0 \%$

Test for overall effect: $Z=0.23(P=0.82)$

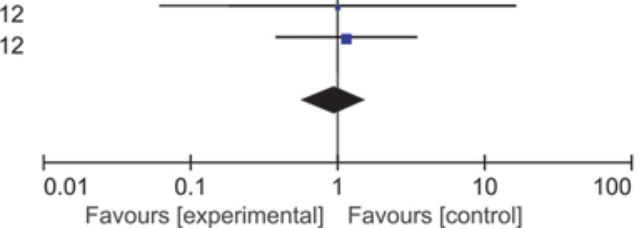

Figure 6. Forest plots revealing differences in the means of a number of variables. Differences in (A) International Prostate Symptom Score; (B) prostate volume; (C) mild to moderate adverse events; and (D) serious adverse events between experimental and control groups. Green squares represent continuous data, while blue squares represent dichotomous data. SD, standard deviation; CI, confidence interval; df, degrees of freedom.

A total of 6 RCTs, involving 1,351 participants (775 in the testosterone group and 576 in the control group), reported upon the number of serious adverse events. TRT did not increase the number of serious adverse events (MD, 0.85; 95\% CI, 0.50 to 1.44 ; $\mathrm{P}=0.55$; Fig. $6 \mathrm{D})$. Similarly, no significant differences were identified upon comparing alternative duration or methods of treatment.

\section{Discussion}

Numerous clinical trials have examined the efficacy and safety of TRT for men with testosterone deficiency based on serum levels (6-21); however, paradoxical results have prevented conclusions from being made. A meta-analysis was therefore conducted of 16 RCTs on aging men with primary or secondary hypogonadism to assess the efficacy and safety of TRT. The present analysis indicated that the patients' quality of life improved markedly following TRT, as indicated by decreased AMS scores, which supports the results of previous studies $(6,25)$. However, conflicting data have been reported in studies regarding the efficacy of TRT treatment upon BMD (26). Mittan et al (27) reported that using TRT during the post-operative period for patients undergoing hypogonadal pituitary tumor surgery may have beneficial effects on the 
Table II. Adverse events.

Mild to moderate adverse events, $\mathrm{n} /$ total $\mathrm{n}$

First author, year (ref.)
Discontinued participants, $\mathrm{n}$

Experimental Control

Serious adverse events $\mathrm{n} /$ total $\mathrm{n}$

\begin{tabular}{|c|c|c|c|c|c|c|}
\hline Idan et al, 2010 (15) & 19 & 14 & $13 / 55$ & $5 / 55$ & $8 / 55$ & $11 / 55$ \\
\hline Ho et al, 2012 (21) & 4 & 2 & $3 / 60$ & $1 / 60$ & $1 / 60$ & $1 / 60$ \\
\hline $\begin{array}{l}\text { Kaufman et al, } \\
2011 \text { (18) }\end{array}$ & 66 & 12 & $134 / 234$ & $15 / 40$ & $5 / 234$ & $1 / 40$ \\
\hline $\begin{array}{l}\text { Emmelot-Vonk } \\
\text { et al, } 2008 \text { (7) }\end{array}$ & 16 & 14 & $104 / 113$ & $105 / 110$ & $5 / 113$ & $10 / 110$ \\
\hline $\begin{array}{l}\text { Srinivas-Shankar } \\
\text { et al, } 2010 \text { (17) }\end{array}$ & 15 & 16 & $10 / 130$ & $7 / 132$ & $6 / 130$ & $3 / 132$ \\
\hline Behre et al, 2012 (6) & 15 & 24 & $12 / 183$ & $10 / 179$ & $7 / 183$ & $6 / 179$ \\
\hline
\end{tabular}

BMD of the spine, but that no significant changes occur in the femoral neck or total femur BMD. The current analysis revealed that TRT had no beneficial effects on BMD in men with hypogonadism without tumors, in contrast with the results of previous studies (28-30). There are three possible reasons for this discrepancy. First, the participants of studies included in the present analysis were selected on the basis of their androgen status, as opposed to their health status or symptoms. The majority of participants in the current study were healthy and had no pre-existing health problems that may have prejudiced results (7). Second, in aging men with low testosterone levels, the effect of TRT on BMD appears to be associated with baseline testosterone levels; testosterone treatment increased BMD only in men whose baseline levels were below the reference range (31). Third, the majority of studies included in the present meta-analysis involved $<2$ years of TRT, while conventional osteoporosis studies typically extend over a 3-year period. BMD following TRT therefore requires additional study.

The present analysis revealed that, compared with the placebo group, TRT significantly increased lean body mass, which was in accordance with previous studies $(25,32)$. Other previous studies $(26,27,32)$ reported that the weight and fat mass of patients with prostate cancer significantly increased and that their lean mass significantly decreased during androgen deprivation therapy. However, in the present analysis, no improvement was identified in body weight and BMI following TRT. Another previous study demonstrated that body weight and BMI improved significantly in men with hypogonadism also exhibiting type 2 diabetes following TRT (28), suggesting that TRT was more efficacious in improving body weight and BMI in patients with type 2 diabetes.

Clinical trials have examined whether exogenous testosterone administration can decrease serum concentrations of high-density lipoprotein cholesterol (HDL-C) (25). As low HDL-C correlates with an increased risk of cardiovascular disease (CVD), this decrease may contribute to the presumed adverse cardiovascular effects of testosterone. By contrast, a previous study demonstrated that low circulating androgen levels in men are associated with increased risk of CVD and mortality (8), which challenges the assumption that testosterone adversely impacts cardiovascular health in men. However, as there were not enough data to analyze the CVD risk following TRT, additional investigative trials are required to determine whether TRT correlates with altered CVD risk.

Prostate growth is dependent on the presence of testosterone; higher serum testosterone is associated with a larger prostate volume and higher prevalence of BPH. Antiandrogens and orchidectomy decrease the prostate volume in patients with BPH $(29,33)$. Previous evidence has indicated that androgens affect prostate volume and the development of prostate cancer (31). The present analysis revealed that prostate volume increased in the testosterone-treated group compared with the placebo group. However, no statistical differences were identified in PSA levels and IPSS in the testosterone-treated group compared with those in the placebo group. Raynaud et al (34) reported that long-term TRT was not associated with significant changes to PSA concentration and PSA velocity or any significant prostate risks. However, Khera et al (32) reported that patients with a baseline total testosterone level of $<250 \mathrm{ng} / \mathrm{dl}$ were more likely to demonstrate increased PSA levels following TRT than those with a baseline total testosterone level of $>250 \mathrm{ng} / \mathrm{dl}$, which supports the prostate saturation hypothesis. In the present meta-analysis, the total testosterone of participants was $<300 \mathrm{ng} / \mathrm{dl}$, and PSA levels and IPSS did not increase following TRT. However, it cannot be concluded that PSA levels and IPSS did not increase following TRT in patients with a baseline total testosterone level of $<50 \mathrm{ng} / \mathrm{dl}$; patients who are severely hypogonadal may experience increased PSA following TRT. The current meta-analysis revealed that prostate volume increased significantly following TRT. The PSA concentration typically demonstrated a greater association with TRT than total prostate volume. The PSA concentration did not increase whilst prostate volume increased significantly; this may be as cell proliferation of the peripheral prostate affected by testosterone is more efficient than the synthesis and secretion of PSA per cell in prostate epithelial cells. This hypothesis conflicts with a previous study reporting that PSA secretion is more rapidly altered by exogenous androgens than prostate growth is (35). The molecular mechanism behind this phenomenon requires additional study. 
A novel and unexpected result of the present study was that mild to moderate adverse events associated with TRT occurred at a greater frequency in TRT patients than in the control group, particularly in patients receiving long-term TRT; this was also true of the transdermal administration group. However, the frequency of serious adverse events did not significantly differ between the testosterone and control groups (Table II). A previous meta-analysis (36) demonstrated that TRT was associated with a significantly higher risk of detection of prostate events and adverse events. However, the frequency of cardiovascular events, sleep apnea and mortality did not significantly increase in the present study.

The 16 RCTs (6-21) included in the current meta-analysis were all double-blind, and the quality of the individual studies in the meta-analysis was high (Fig. 6). The results of these analyses may, therefore, be of great importance from a scientific and a clinical standpoint. However, there are a number of limitations to the present analysis, as follows: i) All 16 RCTs included rigorous periodic monitoring of patients and excluded patients at PSA levels of $>4 \mathrm{ng} / \mathrm{ml}$, which may be why the meta-analysis failed to detect an increased likelihood of prostate cancer amongst patients receiving TRT; ii) differences in testosterone dosage used and baseline PSA levels were reported, which may explain heterogeneity associated with a number of outcomes; and iii) the adverse events of TRT were analyzed, but not enough data were available to assess specific types of adverse events (for instance, gastrointestinal disorders, psychiatric disorders, infections and infestations, muscle and connective tissue disorders or nervous system disorders) that occur following TRT. Any of the aforementioned factors may affect the results of the meta-analysis.

In conclusion, the present meta-analysis indicated that TRT improved the quality of life, increased lean body mass and significantly decreased total cholesterol. In addition, this treatment is well-tolerated and safe for men with hypogonadism who are exhibiting PSA levels of $<4 \mathrm{ng} / \mathrm{ml}$.

\section{Acknowledgements}

The present study was supported by the National Natural Science Foundation of China (grant no. 31100702/C100307) and by the Specialized Research Fund for the Doctoral Program of Higher Education in China (grant no. 20110072120054).

\section{References}

1. Cardarelli R, Singh M, Meyer J, Balyakina E, Perez O and King M: The association of free testosterone levels in men and lifestyle factors and chronic disease status: A North Texas Healthy Heart Study. J Prim Care Community Health 5: 173-179, 2014.

2. Ferreira SR: Cushing and Arquivos Brasileiros de Endocrinologia e Metabologia Award 2006. Arq Bras Endocrinol Metabol 51: 1181, 2007 (In Portuguese).

3. Cui Y, Zong $\mathrm{H}$, Yan $\mathrm{H}$ and Zhang Y: The effect of testosterone replacement therapy on prostate cancer: A systematic review and meta-analysis. Prostate Cancer Prostatic Dis 17: 132-143, 2014.

4. Bassil N: Late-onset hypogonadism. Med Clin North Am 95: 507-523, 2011.

5. Donatucci C, Cui Z, Fang Y and Muram D: Long-term treatment patterns of testosterone replacement medications. J Sex Med 11: 2092-2099, 2014.
6. Behre HM, Tammela TL, Arver S, Tolrá JR, Bonifacio V, Lamche M, Kelly J, Hiemeyer F, Giltay EJ and Gooren LJ; European Testogel Study Team: A randomized, double-blind, placebo-controlled trial of testosterone gel on body composition and health-related quality-of-life in men with hypogonadal to low-normal levels of serum testosterone and symptoms of androgen deficiency over 6 months with 12 months open-label follow-up. Aging Male 15: 198-207, 2012.

7. Emmelot-Vonk MH, Verhaar HJ, Nakhai Pour HR, Aleman A, Lock TM, Bosch JL, Grobbee DE and van der Schouw YT: Effect of testosterone supplementation on functional mobility, cognition, and other parameters in older men: A randomized controlled trial. JAMA 299: 39-52, 2008.

8. Amory JK, Watts NB, Easley KA, Sutton PR, Anawalt BD, Matsumoto AM, Bremner WJ and Tenover JL: Exogenous testosterone or testosterone with finasteride increases bone mineral density in older men with low serum testosterone. J Clin Endocrinol Metab 89: 503-510, 2004.

9. Cavallini G, Caracciolo S, Vitali G, Modenini F and Biagiotti G: Carnitine versus androgen administration in the treatment of sexual dysfunction, depressed mood, and fatigue associated with male aging. Urology 63: 641-646, 2004.

10. Page ST, Amory JK, Bowman FD, Anawalt BD, Matsumoto AM, Bremner WJ and Tenover JL: Exogenous testosterone (T) alone or with finasteride increases physical performance, grip strength, and lean body mass in older men with low serum T. J Clin Endocrinol Metab 90: 1502-1510, 2005.

11. Marks LS, Mazer NA, Mostaghel E, Hess DL, Dorey FJ, Epstein JI, Veltri RW, Makarov DV, Partin AW, Bostwick DG, et al: Effect of testosterone replacement therapy on prostate tissue in men with late-onset hypogonadism: A randomized controlled trial. JAMA 296: 2351-2361, 2006.

12. Vaughan C, Goldstein FC and Tenover JL: Exogenous testosterone alone or with finasteride does not improve measurements of cognition in healthy older men with low serum testosterone. J Androl 28: 875-882, 2007.

13. Aversa A, Bruzziches R, Francomano D, Rosano G, Isidori AM, Lenzi A and Spera G: Effects of testosterone undecanoate on cardiovascular risk factors and atherosclerosis in middle-aged men with late-onset hypogonadism and metabolic syndrome: Results from a 24-month, randomized, double-blind, placebo-controlled study. J Sex Med 7: 3495-3503, 2010.

14. Aversa A, Bruzziches R, Francomano D, Spera G and Lenzi A: Efficacy and safety of two different testosterone undecanoate formulations in hypogonadal men with metabolic syndrome. J Endocrinol Invest 33: 776-783, 2010.

15. Idan A, Griffiths KA, Harwood DT, Seibel MJ, Turner L, Conway AJ and Handelsman DJ: Long-term effects of dihydrotestosterone treatment on prostate growth in healthy, middle-aged men without prostate disease: A randomized, placebo-controlled trial. Ann Intern Med 153: 621-632, 2010.

16. Kalinchenko SY, Tishova YA, Mskhalaya GJ, Gooren LJ, Giltay EJ and Saad F: Effects of testosterone supplementation on markers of the metabolic syndrome and inflammation in hypogonadal men with the metabolic syndrome: The double-blinded placebo-controlled Moscow study. Clin Endocrinol (Oxf) 73: 602-612, 2010.

17. Srinivas-Shankar U, Roberts SA, Connolly MJ, O'Connell MD, Adams JE, Oldham JA and Wu FC: Effects of testosterone on muscle strength, physical function, body composition, and quality of life in intermediate-frail and frail elderly men: A randomized, double-blind, placebo-controlled study. J Clin Endocrinol Metab 95: 639-650, 2010.

18. Kaufman JM, Miller MG, Garwin JL, Fitzpatrick S, McWhirter C and Brennan JJ: Efficacy and safety study of $1.62 \%$ testosterone gel for the treatment of hypogonadal men. J Sex Med 8: 2079-2089, 2011.

19. Shigehara K, Sugimoto K, Konaka H, Iijima M, Fukushima M, Maeda Y, Mizokami A, Koh E, Origasa H, Iwamoto T and Namiki M: Androgen replacement therapy contributes to improving lower urinary tract symptoms in patients with hypogonadism and benign prostate hypertrophy: A randomised controlled study. Aging Male 14: 53-58, 2011.

20. Frederiksen L, Højlund K, Hougaard DM, Brixen K and Andersen M: Testosterone therapy increased muscle mass and lipid oxidation in aging men. Age (Dordr) 34: 145-156, 2012.

21. Ho CC, Tong SF, Low WY, Ng CJ, Khoo EM, Lee VK, Zainuddin ZM and Tan HM: A randomized, double-blind, placebo-controlled trial on the effect of long-acting testosterone treatment as assessed by the Aging Male Symptoms scale. BJU Int 110: 260-265, 2012. 
22. Morgentaler A: Testosterone and prostate cancer: An historical perspective on a modern myth. Eur Urol 50: 935-939, 2006.

23. Moher D, Cook DJ, Eastwood S, Olkin I, Rennie D and Stroup F: Improving the Quality of Reports of Meta-Analyses of Randomised Controlled Trials: The QUOROM Statement. Onkologie 23: 597-602, 2000

24. Oxman AD and Guyatt GH: The science of reviewing research. Ann N Y Acad Sci 703: 125-134, 1993.

25. Bhasin S and Buckwalter JG: Testosterone supplementation in older men: A rational idea whose time has not yet come. J Androl 22: 718-731, 2001.

26. Smith MR: Changes in fat and lean body mass during androgen-deprivation therapy for prostate cancer. Urology 63 742-745, 2004

27. Mittan D, Lee S, Miller E, Perez RC, Basler JW and Bruder JM: Bone loss following hypogonadism in men with prostate cancer treated with GnRH analogs. J Clin Endocrinol Metab 87: 3656-3661, 2002.

28. Hackett G, Cole N, Bhartia M, Kennedy D, Raju J and Wilkinson P; BLAST Study Group: Testosterone replacement therapy improves metabolic parameters in hypogonadal men with type 2 diabetes but not in men with coexisting depression: The BLAST study. J Sex Med 11: 840-856, 2014

29. Roehrborn CG, Siami P, Barkin J, Damião R, Major-Walker K Nandy I, Morrill BB, Gagnier RP and Montorsi F; CombAT Study Group: The effects of combination therapy with dutasteride and tamsulosin on clinical outcomes in men with symptomatic benign prostatic hyperplasia: 4-year results from the CombAT study. Eur Urol 57: 123-131, 2010.
30. Kaplan SA: Re: The effects of combination therapy with dutasteride and tamsulosin on clinical outcomes in men with symptomatic benign prostatic hyperplasia: 4-year results from the CombAT study. J Urol 185: 1384-1385, 2011.

31. Hsing AW, Reichardt JK and Stanczyk FZ: Hormones and prostate cancer: Current perspectives and future directions. Prostate 52: 213-235, 2002.

32. Khera M, Bhattacharya RK, Blick G, Kushner H, Nguyen D and Miner MM: Changes in prostate specific antigen in hypogonadal men after 12 months of testosterone replacement therapy: Support for the prostate saturation theory. J Urol 186: 1005-1011, 2011.

33. Liao CH, Li HY, Chung SD, Chiang HS and Yu HJ: Significant association between serum dihydrotestosterone level and prostate volume among Taiwanese men aged $40-79$ years. Aging Male 15: 28-33, 2012

34. Raynaud JP, Gardette J, Rollet J and Legros JJ: Prostate-specific antigen (PSA) concentrations in hypogonadal men during 6 years of transdermal testosterone treatment. BJU Int 111: 880-890, 2013.

35. Ozata M, Bulur M, Beyhan Z, Sengül A, Saglam M, Turan M, Corakci A and Ali Gundogan M: Effects of gonadotropin and testosterone treatments on prostate volume and serum prostate specific antigen levels in male hypogonadism. Endocr J 44: 719-724, 1997.

36. Calof OM, Singh AB, Lee ML, Kenny AM, Urban RJ, Tenover JL and Bhasin S: Adverse events associated with testosterone replacement in middle-aged and older men: A meta-analysis of randomized, placebo-controlled trials. J Gerontol A Biol Sci Med Sci 60: 1451-1457, 2005 